\title{
Tác động bất ngờ của khoa học công dân đến cuộc sống và thế giói khoa học
}

\author{
Hồ Mạnh Toàn
}

AISDL

Hà Nội (AISDL; 1-1-2019) - Một nghiên cứu mới đây trên tạp chí Citizen Science: Theory and Practice đã phân tích trích dẫn của 143 công bố có phản biện từ 23 dự án khoa học cộng đồng về khoa học vũ trụ và thiên văn. Dựa trên dữ liệu từ Web of Science, 143 công bố này đã có tổng cộng 4515 trích dẫn (Mallapaty, 2018).

\section{Gains in cite}

The average citizen science paper in space science and astronomy achieves a high citation peak within four years of publication, before seeing a sharp drop in impact. The citation rate is more than four times higher than the typical astronomy paper.

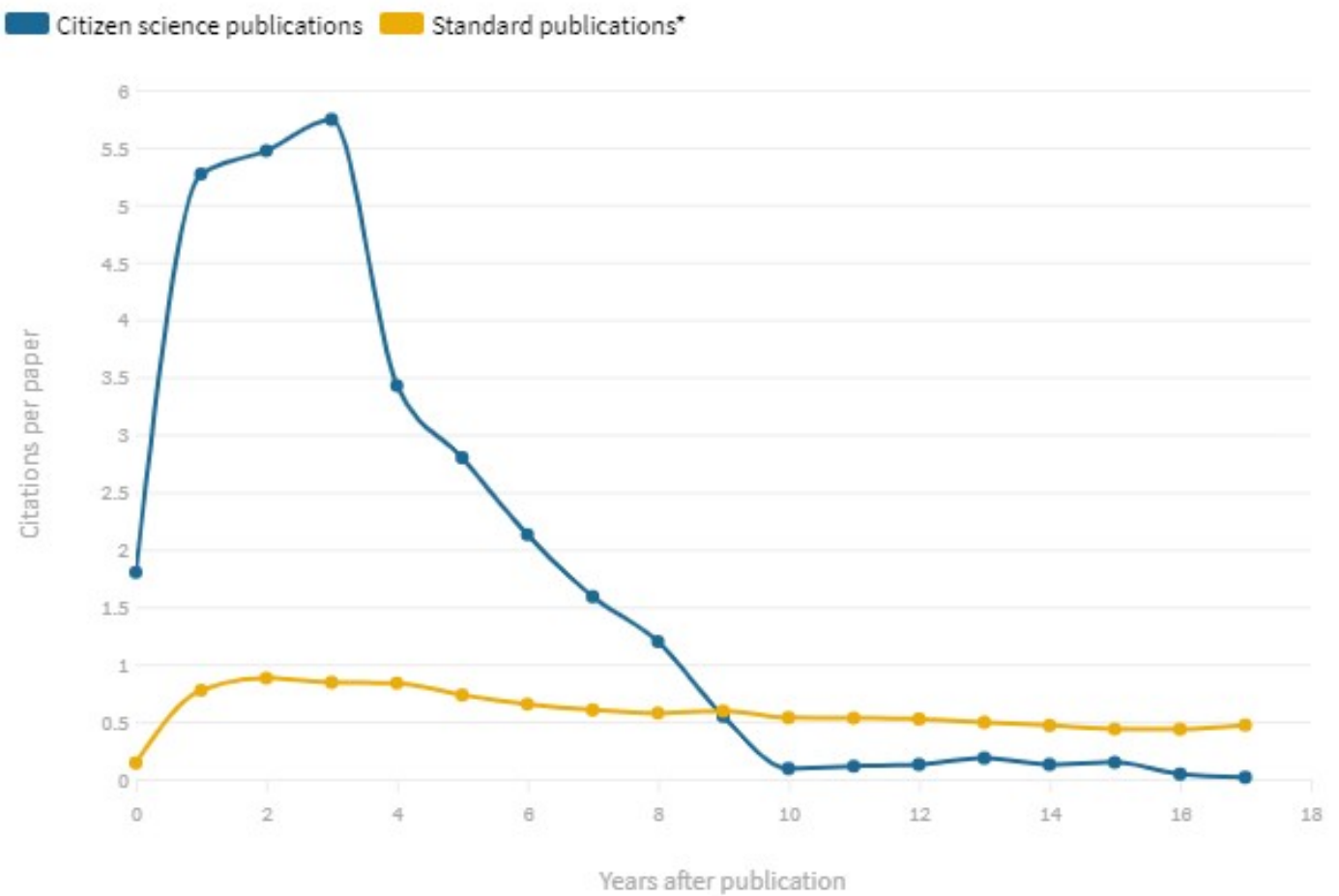

*Based on analysis of papers published in 2000

(Nguồn: NatureIndex; Mallapaty, 2018)

Made with Flourish 
Kết quả phân tích cho thấy, trong khoảng thời gian trung bình 6 năm, có nhiều nghiên cứu từ các dự án khoa học cộng đồng vượt ngưỡng 200 trích dẫn hơn so với các nghiên cứu thông thường. Tuy nhiên, chỉ có khoảng 3 năm đầu tiên là các công bố này được giới khoa học chú ý, đến khoảng năm thứ 8 thì lượng trích dẫn giảm khá mạnh. Điều này trái ngược với các nghiên cứu thông thường khi đạt đỉnh về trích dẫn muộn hơn cũng như có được sự chú ý lâu bền hơn.

Tác giả nghiên cứu Sten Odenwald đánh giá hầu hết các chương trình khoa học cộng đồng này đều hướng đến mục đích giới thiệu, phổ biến kiến thức hơn là sản xuất ra các tác phẩm công bố được. Tuy nhiên, chất lượng các công bố này vẫn ở mức khá tốt, thậm chí vượt mặt nhiều nghiên cứu thông thường về tî lệ trích dẫn (Odenwald, 2018).

Hồi tháng 10 vừa qua, cộng đồng mạng cũng đã khiến các nhà toán học xôn xao khi các thành viên trên diễn đàn 4chan góp công trả lời vấn đề toán học về superpermutation (Griggs, 2018). Một thành viên trên diễn đàn con về phim hoạt hình Nhật Bản Anime đã đặt ra câu hỏi: nếu xem 14 tập phim bằng mọi thứ tự có thể, chuỗi tập ngắn nhất mà bạn có thể xem là gì? Thực tế, đây là một vấn đề khiến các nhà toán học đau đầu từ năm 1993 (Ashlock \& Tillotson, 1993).) và hiện nay, kết quả từ 4 chan đang được sử dụng với hy vọng tìm ra công thức cuối cùng giải quyết vấn đề này.

Rõ ràng, khoa học không hoàn toàn chỉ dành riêng cho một cộng đồng học thuật nhỏ hẹp. Mọi người đều có thể tiếp cận đến các kết quả nghiên cứu, học hỏi phương pháp luận, và mang đến những đóng góp không ngờ tới, dựa trên nguyên lý giá trị chiển lược của serendipity (Napier \& Vuong, 2013).

\section{References:}

Ashlock, D.A., \& Tillotson, J. (1993). Construction of small superpermutations and minimal injective superstrings. Congr. Numerantium 93, 91-98.

Griggs, M.B. (2018). An anonymous 4chan post could help solve a 25-year-old math mystery. The Verge (Oct 24). Retrieved from: https://www.theverge.com/2018/10/24/18019464/4chan-anon-animeharuhi-math-mystery.

Mallapaty, S. (2018). Data brief: Citizen science papers have more impact. NatureIndex, November 23. Retrieved from: https://www.natureindex.com/news-blog/data-brief-citizen-sciencepapers-have-more-impact (truy cập: Dec 25, 2018). 
Napier, N.K., \& Vuong, Q.H. (2013). Serendipity as a strategic advantage?. In Wilkinson (ed) Strategic Management in the 21st Century (Vol. 1: The Operational Environment, pp. 175-199). Westport, CT: Praeger/ABC-Clio.

Odenwald, S. (2018). A Citation Study of Citizen Science Projects in Space Science and Astronomy. Citizen Science: Theory and Practice, 3(2), 5, 1-11. https://doi.org/10.5334/cstp.152

SSHPA SciComm (2018). Ảnh hưởng của cộng đồng đến khoa học. Địa chỉ: https://sc.sshpa.com/post/4363 (truy cập: 30-12-2018) 